\title{
Problem with Dietary Habits in Community-Dwelling Individuals with Spinal Cord Injury in Japan: A Qualitative Study
}

\author{
Kikuko Hata, Wakako Tatsuta, Takayo Inayama* \\ Graduate School of Human Health Sciences, Tokyo Metropolitan University, Tokyo, Japan
}

Email address:

k3.flag@gmail.com (K. Hata), wakatatsu327@gmail.com (W. Tatsuta), tinayama@tmu.ac.jp (T. Inayama)

To cite this article:

Kikuko Hata, Wakako Tatsuta, Takayo Inayama. Problem with Dietary Habits in Community-Dwelling Individuals with Spinal Cord Injury in Japan: A Qualitative Study. International Journal of Nutrition and Food Sciences. Vol. 5, No. 1, 2016, pp. 39-46.

doi: 10.11648/j.ijnfs.20160501.16

\begin{abstract}
The purpose of this study was to develop a model that details "problems with dietary habits" for community-dwelling individuals with spinal cord injury (SCI). We mailed questionnaires to 2,731 registered members of Spinal Injuries Japan that asked the following question: "Is there any problem with your diet, meal, and food? Feel free to write anything." The answer paper had free space in which individuals could freely write their problems with diet, meal, and food. Ultimately, responses from 260 individuals who answered the open-ended question were analyzed. We categorized responses using content analysis. The categories were classified based on the PRECEDE-PROCEED model. A total of 337 items related to "problems with dietary habits" as record units. The record units were classified into seven categories. Five of the seven categories have utility for the PRECEDE-PROCEED model of dietary habits: health/nutritional status, dietary behavior, healthy behavior, reinforcing, and enabling. The two categories not included in the PRECEDE-PROCEED model of dietary habits were excretion and other problems. "Problems with dietary habits" were classified and five of the seven categories form a framework applicable to the PRECEDE-PROCEED model.
\end{abstract}

Keywords: Spinal Cord Injury, Dietary Habits, Problem, Open-Ended Question, PRECEDE-PROCEED Model

\section{Introduction}

Many individuals with spinal cord injury (SCI) participate socially (e. g., through study or work) while leading an unassisted home life. SCI has health risks such as excretion functional disorder and pressure ulcer [1]. Furthermore, SCI has a high risk of preventable illness, such as heart disease, obesity, and metabolic syndrome due to inactivity $[1,2]$. A sensible approach to health promotion [3], particularly regarding nutrition and dietary habits, is very important for individuals with SCI.

There have been a few health promotion intervention studies on individuals with a physical disability, including SCI. For example, studies have focused on social support interventions to decrease weight [4] and to promote a balanced diet and physical activity [5]. In such studies, social support or social capital was shown to be a key factor in health promotion. Therefore, health promotion interventions promote individual effort transformation, and it is necessary that they reflect the actual voice of the person concerned and those who provide support, such as the family and caregivers. In a study using open-ended questions with care providers of individuals with intellectual disabilities, barriers of physical activity, barriers of healthy eating behavior, and strategies to prevent metabolic syndrome were explored [6]. The findings pointed to the importance of breaking down the identified barriers in order to promote physical activity and healthy eating behavior using behavioral science strategies.

The use of the open-ended question differs from surveys in which the response is limited to the choices provided. The open-ended question allows for the individual's opinion or voice. We made use of the merit of an open-ended question to hear the actual voice of community-dwelling individuals with SCI. A feasible health promotion intervention is possible by hearing this actual voice. Therefore, we asked individuals with SCI about their "problems in dietary habits" and had them describe this freely. In asking about "problems," we expected that the responses would include individual effort and social approaches. Furthermore, need for support was a key factor for health promotion interventions that we 
wanted to identify.

To our knowledge, no studies using the open-ended question method have been conducted to examine the dietary habits of community-dwelling adults with SCI. A potential theoretical framework for assessing the dietary needs of this population is the PRECEDE-PROCEED model. The PRECEDE-PROCEED model is an evaluation framework for designing an intervention plan of health promotion [7]. The model describes in detail the process of planning, implementing, and evaluating a health promotion intervention. A fundamental assumption of the model is the active participation of its intended audience, that is, that the participants will take an active part in defining their own problems. In this model, the final goal is quality of life, not health. PRECEDE is an acronym for Predisposing, Reinforcing, and Enabling Constructs in Educational Diagnosis and Evaluation. In the PRECEDE phase there is an assessment of the social, epidemiological, behavioral, environmental, educational, ecological, administrative, and policy factors that need to be addressed in order to develop an intervention. PROCEED is an acronym for Policy, Regulatory, and Organizational Constructs in Educational and Environmental Development. This phase involves the process of implementing the intervention and evaluating the impact and outcome of the intervention. The PRECEDE-PROCEED model of dietary habits comprises the following elements: quality of life, health and nutrition status, dietary behavior (including food intake), health behavior, predisposing (knowledge, attributes, and skills), reinforcing (social support), enabling (access to food and dietary information), and dietary environment [8]. It is not confirmed whether the problems with dietary habits of community-dwelling individuals with SCI can be classified using the PRECEDE-PROCEED model of dietary habits.

By classifying the needs for nutrition and the dietary habits using the PRECEDE-PROCEED model, we can develop a model of health promotion intervention for persons with SCI living in the community. Therefore, the purpose of this qualitative study was to identify the problems that persons living in the community with SCI have with regard to their dietary habits and incorporate the findings into the PRECEDE-PROCEED model of dietary habits.

\section{Methods}

\subsection{Subjects and Procedures}

This study analyzed data collected in a previous study titled "Key dietary behavioral and environmental factors mediating dietary variety among Japanese adults with spinal cord injury" [9] and "Vegetable dishes, dairy products and fruits are key items mediating adequate dietary intake for Japanese adults with spinal cord injury" [10]. The target group included community-dwelling individuals with SCI. In September 2011, we mailed questionnaires to 2,731 registered members of the Spinal Injuries Japan (SIJ) organization. SIJ has 45 branch offices across the country; they perform activities such as reporting on spinal cord injury and offering peer support. With regard to the attributes of registered members, the average age is approximately 65 years, $80 \%$ are men, and the most common lesion type is thoracic spinal cord injury followed by cervical cord and lumbar spinal cord injury.

\subsection{Research Question}

We asked a single question: "Is there any problem with your diet, meal, and food? Feel free to write anything." An answer paper had free space for individuals to write freely about any problems with diet, meal, and food.

\subsection{Sociodemographic Variables}

Data regarding participants' sex, age $(\leq 39,40-64$, or $\geq 65$ years), years since injury, lesion type (cervical cord injury, thoracic spinal cord injury, or lumbar spinal cord injury), living status (living alone or living with others), social participation (yes or no), and current use of welfare services and support (yes or no) were obtained from the completed questionnaires.

\subsection{Data Analysis}

We received questionnaires from 1,000 individuals (37\% response rate). First, we excluded those questionnaires in which crucial data such as sex, age, lesion type, and type of disability were missing. Next, we divided the questionnaires into two groups: the response group and the non-response group to the open-ended question. Ultimately, the response group included 260 individuals whose responses were analyzed ( $10 \%$ valid response rate).

We conducted the analysis according to the content analysis method of Berelson [11]. We encoded the descriptions for the 260 individuals by sentence. When the sentence did not answer the question of "problem with dietary behavior," it was excluded. One sentence was considered one record unit of "problem with dietary habits." Similar record units were divided into subcategories. Content analysis, according to Bryman [12], is an analytic approach that attempts to "quantify content in terms of predetermined categories and in a systematic and replicable manner" [13]. Therefore, we counted the appearance frequency of a subcategory and category in this study. The categories were classified in reference to the PRECEDE-PROCEED model.

First, a researcher in the field of community nutrition and registered dietician created the record unit and subcategory. Next, we requested two researchers in the field of community nutrition, also registered dieticians, to create a record unit and subcategory. The reliability of the categories was examined using Scott's equation [14]. We adopted a minimum rate of $70 \%$ based on a previous study on patients with SCI [15] and the rationale described by Funashima who stated "when a category shows a rate of Scott's pi of more than $70 \%$, a category secures reliability" [16]. In addition, the subcategories and classification of responses into the categories involved consultation between researchers until a unified opinion was obtained. 
Table 1. Sample characteristics.

\begin{tabular}{llll}
\hline & & $\mathbf{n = 2 6 0}$ & $\mathbf{( \% )}$ \\
\hline Sex & Men & 198 & $(76.2)$ \\
\multirow{4}{*}{ Age group } & Women & 62 & $(23.8)$ \\
& $\leq 39$ years & 22 & $(8.5)$ \\
& 40-64 years & 147 & $(56.5)$ \\
Lesion type & $\geq 65$ years & 91 & $(35.0)$ \\
& Cervical cord injury & 84 & $(32.3)$ \\
& Thoracic cord injury & 126 & $(48.5)$ \\
Living status & Lumbar cord injury & 50 & $(19.2)$ \\
\multirow{2}{*}{ Social participation } & Living alone & 43 & $(16.5)$ \\
& Living with others & 217 & $(83.5)$ \\
Current use of welfare & Yes & 173 & $(72.7)$ \\
services and support & Yes & 65 & $(27.3)$ \\
& No & 108 & $(44.1)$ \\
\hline
\end{tabular}

Missing values were excluded for each item.

\subsection{Statement of Ethics}

The study was approved by the ethical committee of Tokyo Metropolitan University (Certification number 23-18).

\section{Results}

\subsection{Sample Characteristics}

The subjects' mean age was $58.4(\mathrm{SD}=12.7)$ years. The mean number of years since injury was $25.6(\mathrm{SD}=13.9)$ years. Of the respondents, $48.5 \%, 32.3 \%$, and $19.2 \%$ had suffered thoracic, cervical, and lumbar injuries, respectively (see Table 1 ). We compared the distribution of the open-ended question of the non-response group $(n=630)$ with the response group $(n=260)$. The response group had a higher ratio of women than the non-response group $(23.8 \%$ vs. $11.4 \%)$. There were no other notable differences between the groups.

\section{2. "Problem with Dietary Habits" Categories}

A total of 337 items related to "problem with dietary habits" from the record units of 260 subjects. The record units were classified into seven categories and 31 subcategories (see Table 2). The rate of agreement was high, with Scotto's pi indicating an interrater reliability of $91 \%$. The seven categories and related subcategories that were derived are as follows:

1) Health/nutritional status: weight gain, edible quantity is limited to once (little quantity), hard to feel sense of hunger, illness other than lifestyle-related disease, lifestyle-related disease, dysphagia, pain/numbness, weight loss, and pressure ulcer.

2) Excretion: relationship between excretion and diet, defecation control, excretion and going out, and defecation time.

3) Dietary behavior: not understanding the aim of the intake, meal preparation, excess and deficiency of food, overeating, meal balance, breakfast intake, assistance is necessary and a meal is not edible independently, unbalanced diet, time to eat a meal, speed-eating, and snacking.

4) Healthy behavior: physical activity and drinking alcohol.

5) Reinforcing: social support.

6) Enabling: access to food, and access to dietary information.

7) Other problems: future uneasiness and economic condition.

The number of record units per category were as follows: 83 health/nutritional status items, 70 excretion items, 133 dietary behavior items, 10 healthy behavior items, 17 reinforcing items, 20 enabling items, and 10 other problems items. The largest number of record units for a subcategory was 31 items for relationship between excretion and diet.

Table 2. Problems with Dietary Habits of Community-Dwelling Individuals with Spinal Cord Injury.

\begin{tabular}{|c|c|c|c|}
\hline Category (record unit count) & Subcategory & $\begin{array}{l}\text { Record } \\
\text { unit count }\end{array}$ & Example record unit \\
\hline \multirow[t]{8}{*}{ Health/nutritional status (83) } & Weight gain & 21 & $\begin{array}{l}\text { It is easy for me to gain weight after injury. } \\
\text { I refrain from meals, but the weight increases. }\end{array}$ \\
\hline & $\begin{array}{l}\text { Edible quantity is limited to } \\
\text { once (little quantity) }\end{array}$ & 18 & $\begin{array}{l}\text { I feel sated immediately, though I eat only a little. } \\
\text { A stomach always swells and does not want to eat. }\end{array}$ \\
\hline & $\begin{array}{l}\text { Hard to feel sense of } \\
\text { hunger }\end{array}$ & 10 & $\begin{array}{l}\text { There is no appetite because I can't feel hungry. } \\
\text { There is no sense of hunger; I worry about the quantity of an } \\
\text { appropriate meal. }\end{array}$ \\
\hline & $\begin{array}{l}\text { Illness other than } \\
\text { lifestyle-related disease }\end{array}$ & 8 & $\begin{array}{l}\text { Orthostatic hypotension is caused after a meal. } \\
\text { Diet cure of cholelithiasis. }\end{array}$ \\
\hline & Lifestyle-related disease & 6 & $\begin{array}{l}\text { Blood pressure has begun to rise. } \\
\text { Because of diabetes, blood sugar level rises from a meal immediately. }\end{array}$ \\
\hline & Dysphagia & 5 & It is hard to swallow, and a hard thing is not edible. \\
\hline & Pain/Numbness & 4 & There is no energy to eat in severe pain. \\
\hline & Weight loss & 3 & The weight continues to decrease. \\
\hline Excretion (70) & $\begin{array}{l}\text { Relationship between } \\
\text { excretion and diet }\end{array}$ & 31 & $\begin{array}{l}\text { When a day without a bowel movement continues, a meal is not } \\
\text { edible. } \\
\text { Because control of a bowel movement and urination is difficult, the } \\
\text { quantity of the meal, the number of meals, and the choice of contents } \\
\text { are difficult. } \\
\text { When I drink milk, I have loose bowels. }\end{array}$ \\
\hline
\end{tabular}




\begin{tabular}{|c|c|c|c|}
\hline Category (record unit count) & Subcategory & $\begin{array}{l}\text { Record } \\
\text { unit count }\end{array}$ & Example record unit \\
\hline \multirow{14}{*}{ Dietary behavior (133) } & Defecation control & 24 & $\begin{array}{l}\text { Bowel movement control is difficult because of constipation and the } \\
\text { repeating of soft bowel movement. } \\
\text { I am troubled with constipation. }\end{array}$ \\
\hline & Excretion and going out & 10 & $\begin{array}{l}\text { A meal is not eaten when going out because of a bowel movement. } \\
\text { There is uneasiness of the excretion, and I cannot eat happily for } \\
\text { worrying at the time of eating out. }\end{array}$ \\
\hline & Defecation time & 5 & It takes a long time to defecate. \\
\hline & $\begin{array}{l}\text { Not understanding the aim } \\
\text { of the intake }\end{array}$ & 30 & $\begin{array}{l}\text { We don't understand necessary energy intake per day, it is expected } \\
\text { that SCIs are different from able-body individuals in energy intake. } \\
\text { It is unknown what quantity we should eat or how much of a meal at } \\
\text { once. }\end{array}$ \\
\hline & Meal preparation & 27 & $\begin{array}{l}\text { I work hard and have a single life, therefore it is difficult for me to buy } \\
\text { foods and cook some meals. } \\
\text { I prepare meals by myself, and I watch food by myself and cannot buy } \\
\text { it. }\end{array}$ \\
\hline & $\begin{array}{l}\text { Excess and deficiency of } \\
\text { food }\end{array}$ & 19 & $\begin{array}{l}\text { I want to eat a lot of vegetables, fish, and fruit, but I feel that there is } \\
\text { little quantity of these to eat. } \\
\text { I consume salt too much. }\end{array}$ \\
\hline & Overeating & 12 & $\begin{array}{l}\text { There is much eating out, quantity of meal increases. } \\
\text { I eat too much of my favorite foods. }\end{array}$ \\
\hline & Meal balance & 10 & $\begin{array}{l}\text { I think about balance and eat a meal, but do not know whether it is } \\
\text { right. } \\
\text { I don't understand how much quantity of staple food, main dish, and } \\
\text { side dish I should eat. }\end{array}$ \\
\hline & Breakfast intake & 9 & $\begin{array}{l}\text { I don't eat breakfast, because I go to bed late every night from work } \\
\text { and get up in the morning slowly. } \\
\text { I am ill conditioned in the morning (orthostatic hypotension), and I } \\
\text { cannot eat breakfast. }\end{array}$ \\
\hline & $\begin{array}{l}\text { Assistance is necessary and } \\
\text { a meal is not edible } \\
\text { independently }\end{array}$ & 8 & $\begin{array}{l}\text { My arm does not rise and cannot be used well with a spoon and fork. } \\
\text { Hands are not usable, and I cannot eat freely. }\end{array}$ \\
\hline & Unbalanced diet & 7 & I dislike vegetables, and I cannot eat vegetables. \\
\hline & Time to eat a meal & 5 & Missed the timing of eating a meal, it becomes irregular. \\
\hline & Speed-eating & 3 & A time to eat a meal is early. \\
\hline & Snacking & 3 & I like sweets, and I eat many snacks. \\
\hline \multirow[t]{2}{*}{ Healthy behavior (10) } & Physical activity & 5 & Lack of exercise. \\
\hline & Drinking alcohol & 5 & $\begin{array}{l}\text { Much quantity of drinking. } \\
\text { Drinking alcohol too much to relieve pain. }\end{array}$ \\
\hline Reinforcing (17) & Social support & 17 & $\begin{array}{l}\text { Because a care service has a limit, having a meal slowly is not } \\
\text { possible. } \\
\text { I cannot give advice to family about meals. }\end{array}$ \\
\hline \multirow[t]{2}{*}{ Enabling (20) } & Access to food & 15 & $\begin{array}{l}\text { The box packed lunch has thick seasoning, and there are few } \\
\text { vegetables. } \\
\text { If we look for and purchase food at a nearby shop, we can satisfy } \\
\text { dietary habits more. }\end{array}$ \\
\hline & $\begin{array}{l}\text { Access to dietary } \\
\text { information }\end{array}$ & 5 & $\begin{array}{l}\text { I don't understand the calculation of the salt intake. } \\
\text { There is no menu that would be helpful. }\end{array}$ \\
\hline \multirow[t]{2}{*}{ Other Problems (10) } & Future uneasiness & 6 & $\begin{array}{l}\text { When there are changes in my family constitution, the current dietary } \\
\text { habits become difficult or less easy. }\end{array}$ \\
\hline & Economic condition & 4 & Much money is not spent on food expenses. \\
\hline
\end{tabular}

\section{Discussion}

The results regarding "problem with dietary habits" of individuals with SCI are generally consistent with the PRECEDE-PROCEED model on dietary habits. However, some categories were not in line with the model. Seven categories were derived through content analysis: health/nutritional status, excretion, dietary behavior, healthy behavior, reinforcing, enabling, and other problems. Two of the categories, excretion and other problems, do not coincide with the dietary habits model. To our knowledge, this is the first study to clarify the dietary problems of individuals with SCI using the open-ended question method and based on the PRECEDE-PROCEED model on dietary habits. This knowledge can assist in further developing the PRECEDE-PROCEED model to design health promotion programs for this population. Our findings on the seven categories are discussed below.

\subsection{Health/Nutritional Status}

The subcategory with the largest number of record units was weight gain. There were responses such as "It is easy for me to gain weight after injury" and "I refrain from meals, but 
the weight increases." In many individuals with SCI, blood pressure and total cholesterol level increases after returning home after injury [2]. Individuals with SCI are advised about weight increase during rehabilitation because lifting oneself into a wheelchair becomes more difficult. On the other hand, there was the subcategory of weight loss. There is the report that weight control becomes troublesome with aging [15]. The average age of the participants in this study was 58 years old, and the years since injury was an average of 25 years. After individuals with SCI leave the hospital and return home, opportunities to receive advice about weight control decrease. Therefore, it is possible that weight control becomes troublesome. It is recommended that a supportive environment and interventions be provided or developed to support efforts at weight control among community-dwelling individuals with SCI.

There were 18 record units for the subcategory of edible quantity is limited to once (little quantity). Other subcategories related to problems with eating were dysphagia, which makes it physically difficult to eat, and hard to feel sense of hunger, which is about poor appetite. The subcategory of pressure ulcer relates to concerns about diet because they are easy to develop in persons with SCI who may spend too much time immobile. Furthermore, these problems with appetite or being able to eat are associated with the subcategory of weight loss. We need to clarify the cause when food is not edible or there are problems with appetite, and consider ways of coping and the needed intervention.

As for the subcategory of lifestyle-related disease, prevention is strongly recommended in the National Health Promotion Policy in Japan. Individuals with SCI have a high morbidity risk of lifestyle-related diseases, and it is necessary to develop and address prevention efforts. Pain/numbness and illness except the lifestyle-related disease were two other problem areas that affected dietary habits. Illness and pain are medical domains. It is necessary to develop an intervention plan for dietary habits for the person with SCI in cooperation with medical staff and medical institutions.

\subsection{Excretion}

The category of excretion could be a subcategory of health/nutritional status. However, there were 70 record units on excretion, so we considered it an independent category that relates to a special problem of dietary habits for individuals with SCI. With SCI, the bladder and rectum are often defective because of paralysis of the spinal cord, and it has been shown that excretion problems lead to social disadvantage [17]. The subcategory that had 55 record units was relationship between excretion and diet. This problem may be about being careful in choosing what foods to eat, because there were many descriptions about diarrhea and constipation. If individuals with SCI must deal with the dietary problem of excretion, reducing the physical and mental burden it causes should be an area of health promotion intervention.

\subsection{Dietary Behavior}

The subcategory with the most number of descriptions concerned not understanding the aim of the intake. The following responses are examples of this subcategory: "We don't understand necessary energy intake per day" and "It is unknown what quantity we should eat or how much of a meal at once." It is expected that individuals with SCI will be different from able-body individuals with regard to energy or nutrient intake. Able-body individuals can refer to the Dietary Reference Intake for the amount of daily estimated energy required [18]. In addition, able-body individuals can use the food balance guide that is a semi quantitative guide [19]. However, individuals with SCI do not have a standard for their dietary habits. With regard to nutrition, research showed that the calcium and vitamin D intake of individuals with chronic spinal cord injury was less than that of able-body individuals [20], calling attention to the need for further research on the dietary intake of persons with SCI. Individuals with SCI and their caregivers would benefit from a guide on healthy dietary habits that shows standards for quantity of food and a meal guide specific for individuals with SCI. Furthermore, such dietary guides would be a useful medium for nutrition education when planning or providing an intervention program.

Several descriptions concerned problems related to meal preparation. It is expected that there would be some difficulty with preparing a meal and going shopping for food, because SCI can result in paralysis in the feet and hands. However, there was a record unit describing the problem of "I work hard and have a single life; therefore, it is difficult for me to buy foods and cook some meals." Therefore, it is necessary to distinguish the cause of the problem as being one's disability, one's lifestyle, or possibly both. People who are single have poorer dietary habits than people living together [21]. As such, an environment in which it is easier for people who are living alone or who are single to prepare meals, with or without a disability, is necessary.

The subcategory of excess and deficiency of food was identified. In particular, there were many answers that pointed to there being very few vegetables, fish, and fruit. Lieberman et al. [20] reported that individuals with chronic SCI in the U.S. consumed fewer dairy, fruit, and whole grain foods than the recommended quantity in the Dietary Guidelines for Americans. The respondents understood healthy dietary habits, but such foods were not eaten even if they wanted to eat them. It is necessary to clarify the reason as to why these foods are not eaten even though people want to eat them.

For the subcategories of overeating, meal balance, breakfast intake, unbalanced diet, time to eat a meal, speed eating, and snacking, these problems with dietary habits are found in able-body persons as well. Solutions can be found on the web and in books. It is necessary to investigate reasons for why individuals with SCI cannot transform their dietary behavior. Is it that they know the information but cannot change their dietary behavior? Do they not know about the information? Do they think the information does not apply to them because 
of their SCI? These questions can guide future research on the dietary behavior of individuals with SCI.

\subsection{Healthy Behavior}

Dietary habits and physical activity are closely related. For the physical activity subcategory, "lack of exercise" was mentioned as a problem. Because it affects activities of daily living (ADL), individuals with SCI want to prevent weight gain. Weight control is difficult by diet alone. It is also necessary to increase physical activity from the viewpoint of ADL. It is recommended that individuals with a physical disability play sports, for social participation as well as prevention of lifestyle-related diseases [22]. Therefore, an intervention program addressing physical activity, exercise, and dietary habits is particularly important for individuals with SCI.

For the problem of "drinking alcohol too much to relieve pain," we could not quantify the quantity of alcohol that can contribute to the palliation of numbness and pain. Moderate drinking is associated with healthy dietary habits and mental health [23]. Nonetheless, "too much" drinking of alcohol is a problem that has serious consequences. It would be important to investigate the cause behind excessive drinking and promote substitute behaviors for the drinking, as well as methods to alleviate numbness and pain.

\subsection{Reinforcing}

There was one subcategory for reinforcing, which was social support. Social support responses mainly concerned caregivers and family relations. One example provided was, "Because a care service has a limit, having a meal slowly is not possible." We thought that if individuals with SCI do not feel satisfaction with the care service, the caregiver was also not satisfied. It is necessary to pay attention to the views of both the person concerned and the caregiver, to offer satisfactory care service for individuals with SCI. The issue of family relations does not only involve dietary habits. For example, there was the response "Because a parent is old, it is necessary for me to care." Each person with a disability may have one or more family members who need his or her help or support. Additionally, it may be necessary to have respite care regarding dietary habits, so that care from the family does not become a disincentive for health promotion for individuals with SCI. Social support and social capital contribute to the health promotion of individuals with SCI, as indicated by the intervention program for overweight/obese persons with SCI [4]. It will be necessary to clarify the content of effective support in health promotion interventions in the future.

\subsection{Enabling}

There were two subcategories for enabling: access to food, and access to dietary information. In Japan, the development of a healthy food environment has been promoted [8]. For example, providing a healthy menu and indicating the composition of foods has increased in shops [8]. Regarding access to food, the issue of "The box packed lunch has thick seasoning, and there are few vegetables" is a problem at the country level that is a part of meal environment maintenance. On the other hand, the problem of "If we look for and purchase food at a nearby shop, we can satisfy dietary habits more" is a problem with the dietary environment particular to individuals with SCI. In some cases, grocery stores are not barrier-free, making it difficult for going food shopping. For the subcategory of access to dietary information, the issue of "I don't understand the calculation of the salt intake," and "There is no menu that would be helpful" is related to what was mentioned previously with regard to the category of dietary behavior in terms of access to both food and dietary information. There is a need for verification of whether individuals with SCI are aware of meal environment maintenance currently underway in Japan. It is expected that the development of a food environment that is supportive to individuals with SCI would have a positive influence on their dietary behavior. Such interventions are needed to address issues that were identified under the category of enabling. In addition, investigation of the health literacy of individuals with SCI is necessary in future research, because there is evidence that health literacy is strongly related to health behavior [24].

\subsection{Other Problems}

Two items not classified within the framework of dietary habits were future uneasiness and economic condition. The employment rate of individuals with a physical disability in Japan is $20-30 \%$ lower than for able-body persons [25]. There are individuals with a disability who can live on only a pension for people with a disability (without the work). However, economic conditions do not often consider health restrictions, because some people cannot work even if they want to work. The influence of income and education on the health disparities in Japan has been an important area of research investigation [26], and National Health Promotion Policy in Japan is the "extension of healthy life expectancy and reduction of health disparities" [8]. In our previous study, we reported that individuals with SCI with social participation and social support had high self-rated health and dietary satisfaction [27]. Given research indicating that a person with a disability often has little social support [28], social participation and social support with a connection to society are necessary. Having employment opportunities and a social support system will help alleviate uneasiness and economic conditions in the future. Creating a supportive environment and promoting social participation for individuals with a disability may be a solution to their uneasiness and economic condition.

\subsection{Study Limitations}

This study was subject to several limitations. First, the sample population was recruited from the membership of the SIJ organization. Therefore, our findings may not be representative of the overall population of individuals with 
chronic SCI in Japan. Second, it is unknown whether this study covered all problems in dietary habits of individuals with SCI. Third, the categories derived in this study for the PRECEDE-PROCEED model may be appropriate or relevant for other populations, not just individuals with SCI. Finally, in this study we did not investigate the opinions of individuals of support, such as family members and caregivers.

Despite these limitations, in this study, we explored using various classification models for the categories; for example, the World Health Organization's International Classification of Functioning, Disability, and Health model [29] and the empowerment model [30]. However, a PRECEDE-PROCEED model was the best fit. The results were incorporated into a framework based on our thinking about a health promotion intervention useful for individuals with SCI. However, the issues that were not included in the framework are excretion, economic conditions, and uneasiness in the future. It is necessary to incorporate these issues into a theoretical framework when we evaluate dietary habits of individuals with SCI in future research. This study is a valuable report that exhibited the problem of dietary habits in individuals with SCI. Future research should investigate the findings in this study quantitatively to clarify a system of dietary habits that support individuals with SCI. In addition, we clarified ways to support specific dietary habits in community-dwelling individuals with SCI and develop a health promotion intervention program to address the needs of this population.

\section{Conclusions}

The purpose of this study was to incorporate the findings into the PRECEDE-PROCEED model as "problems with dietary habits" for community-dwelling individuals with SCI. "Problem with dietary habits" of community-dwelling individuals with SCI were generally consistent with the PRECEDE-PROCEED model on dietary habits. Seven categories were derived through content analysis: health/nutritional status, excretion, dietary behavior, healthy behavior, reinforcing, enabling, and other problems. Two of the categories, excretion and other problems, do not coincide with the dietary habits model. This knowledge can assist in further developing the PRECEDE-PROCEED model to design health promotion programs for this population.

\section{Acknowledgments}

We wish to thank all the individuals with SCI who participated in this study. This work was supported by JSPS KAKENHI Grant Number 23500962.

\section{References}

[1] Garshick E, Kelley A, Cohen SA, Garrison A, Tun CG, Gagnon D, Brown R. A prospective assessment of mortality in chronic spinal cord injury. Spinal Cord 2005; 43: 408-416.
[2] De Groot S, Post MW, Snoek GJ, Schuitemaker M, van der Woude LH. Longitudinal association between lifestyle and coronary heart disease risk factors among individuals with spinal cord injury. Spinal Cord 2013; 51: 314-318.

[3] Reichard A, Stolzle H, Fox MH. Health disparities among adults with physical disabilities or cognitive limitations compared to individuals with no disabilities in the United States. Disabil Health J 2011; 4: 59-67.

[4] Chen Y, Henson S, Jackson AB, Richards JS. Obesity intervention in persons with spinal cord injury. Spinal Cord 2006; 44: 82-91.

[5] Rimmer JH, Wang E, Pellegrini CA, Lullo C, Gerber BS. Telehealth weight management intervention for adults with physical disabilities: A randomized controlled trial. Am J Phys Med Rehabil 2013; 92: 1084-1094.

[6] Arai H., Kojima H., Yamazaki Y. An exploratory study to prevent metabolic syndrome for individuals with intellectual disabilities. JSHEP 2011; 19: 15-25. (in Japanese). https://www.jstage.jst.go.jp/article/kenkokyoiku/19/1/19_15/_ pdf (accessed October 2015).

[7] Green LW, Kreuter MW. Health Program Planning: an Educational and Ecological Approach, 4th ed. Boston: Mc Graw Hill; 2005.

[8] Ministry of Health, Labour and Welfare (2012) A Basic Direction for Comprehensive Implementation of National Health Promotion. http://www.mhlw.go.jp/file/06-Seisakujouhou-10900000-Ken koukyoku/0000047330.pdf. (accessed September 2015).

[9] Tsunoda N, Inayama T, Hata K, Oka J. Key dietary behavioral and environmental factors mediating dietary variety among Japanese adults with spinal cord injury. Int J Nutr Food Sci 2015; 4: 111-117.

[10] Tsunoda N, Inayama T, Hata K, Oka J. Vegetable dishes, dairy products and fruits are key items mediating adequate dietary intake for Japanese adults with spinal cord injury. Spinal Cord. 2015; 53: 786-790.

[11] Berelson B. Content analysis in communication research. Glencoe: Ill, Free Press; 1952.

[12] Bryman A. Social research methods, 4th edn. Oxford University Press; 2012.

[13] Liamputtong P, Serry T. Research methods in health 2nd edn. Oxford University Press; 2013.

[14] Scott WA. Reliability of content analysis: the case of nominal scale coding. Public Opin Q 1995; 19: 321-325.

[15] Shimokariya M, Yatsushiro R. Problems in home care for patients with spinal cord injuries during the 10 years following discharge. JJOMT 2011; 59: 137-142. (in Japanese). http://www.jsomt.jp/journal/pdf/059030137.pdf (accessed October 2015).

[16] Funashima N. Challenge to a qualitative study, 2nd ed. Tokyo: IGAKU-SHOIN; 2007. (in Japanese).

[17] Aoyagi N, Takahashi H, Hara Y, Shibazaki K, Liu M, Chino N. Factors associated with handicaps of spinal cord injured patients: Pilot Study of the CHART. Jpn J Rehabil Med 1999; 36: 599-606. (in Japanese).

https://www.jstage.jst.go.jp/article/jjrm1964/36/9/36_9_599/_ pdf (accessed October 2015). 
[18] Ministry of Health, Labour and Welfare. Overview of Dietary Reference Intakes for Japanese (2015). http://www.mhlw.go.jp/file/06-Seisakujouhou-10900000-Ken koukyoku/Overview.pdf. (accessed October 2015).

[19] Yoshiike N, Hayashi F, Takemi Y, Mizoguchi K, Seino F. A new food guide in Japan: the Japanese food guide Spinning Top. Nutr Rev 2007; 65: 149-154.

[20] Lieberman J, Goff D Jr, Hammond F, Schreiner P, Norton HJ, Dulin M, Zhou X, Steffen L. Dietary intake and adherence to the 2010 Dietary Guidelines for Americans among individuals with chronic spinal cord injury: A pilot study. J Spinal Cord Med 2014; 37: 751-757.

[21] Ministry of Health, Labour and Welfare. National Health and Nutrition Survey in Japan 2013. http://www.mhlw.go.jp/bunya/kenkou/eiyou/dl/h25-houkoku. pdf (accessed October 2015).

[22] US Department of Health and Human Services. The Surgeon General's call to action to improve the health and wellness of persons with disabilities: Calling you to action. Office of the Surgeon General, Washington DC: US Department of Health and Human Services; 2005.

[23] Marmot MG, Rose G, Shipley MJ, Thomas BJ. Alcohol and mortality: A U-shaped curve. Lancet 1981; 1: 580-583.

[24] Berkman ND, Sheridan SL, Donahue KE, Halpern DJ, Viera A, Crotty K, et al. Health literacy interventions and outcomes: An updated systematic review. Evid Rep Technol Assess 2011; (199): 1-941.
[25] Cabinet Office Japan. Annual Report on Government Measures for Persons with Disabilities (Summary) 2014: Chapter 5 Building Foundations of Independence toward Social Participation. http://www8.cao.go.jp/shougai/english/annualreport/2014/pdf/ s5.pdf. (accessed October 2015).

[26] Kagamimori S, Gaina A, Nasermoaddeli A. Socioeconomic status and health in the Japanese population. Soc Sci Med 2009; 68: $2152-2160$.

[27] Hata K, Inayama T, Matsushita M, Shinoda S. The combined associations of social participation and support with self-rated health and dietary satisfaction in men with spinal cord injury. Spinal Cord 2015; doi: 10.1038/sc.2015.166.

[28] Mithen J, Aitken Z, Ziersch A, Kavanagh AM. Inequalities in social capital and health between people with and without disabilities. Soc Sci Med. 2015; 126: 26-35.

[29] World Health Organization. How to use the ICF: A practical manual for using the International Classification of Functioning, Disability and Health (ICF). Exposure draft for comment. http://www.who.int/classifications/icf/icf_more/en/ (accessed October 2015).

[30] World Health Organization, TDR empowerment function: empowerment: annual report 2008. http://apps.who.int/iris/bitstream/10665/70104/1/TDR BL2.0 8 _eng.pdf?ua $=1$. (accessed October 2015). 